\title{
La Historia, la Ciencia y la Nación. Un estudio de caso en el México decimonónico
}

\author{
Frida Gorbach (*) \\ ${ }^{*}$ ) Universidad Autónoma Metropolitana, Xochimilco \\ frida.gorbach@gmail.com
}

Dynamis

[0211-9536] 2013; $33(1): 119-138$
Fecha de recepción: 16 de abril de 2012

Fecha de aceptación: 6 de noviembre de 2012

SUMARIO: 1.—Porfirio Parra, el caso. 2.—La Ciencia. 3.—La Historia. 4.—La Nación.

RESUMEN: En un intento por reflexionar alrededor de la dimensión política del conocimiento, me acerco al discurso médico mexicano de finales del siglo XIX y me pregunto por la relación entre historia, ciencia y nación, tres conceptos que en una trama difícil de desentrañar delinean de muchas formas el vínculo que la modernidad construyó entre naturaleza, política e historia. Tomo para ello el caso de Porfirio Parra, uno de los pocos médicos que en México reflexionó alrededor de los métodos, los principios y las reglas del conocimiento científico, y, desde un ángulo de su vasta obra, intento mostrar cómo en su concepción de ciencia, la nación y la historia constituyen actores insoslayables.

PALABRAS CLAVE: ciencia, positivismo, historia, nación, raza, México.

KEYWORDS: science, positivism, history, nation, race, Mexico.

\section{Porfirio Parra, el caso}

En años recientes se ha despertado en México el interés por estudiar la relación entre los discursos científicos y la idea de nación y, en este sentido, ya muy pocos pueden esquivar la pregunta por las relaciones entre saber y poder ni dejar de lado la necesidad de desenmascarar la ideología a través de la cual la ciencia europea adquirió sentido en México ${ }^{1}$.

1. Al respecto ver especialmente el análisis de las políticas eugénicas de la primera mitad del siglo XX en México de Urías Horcasitas, Beatriz. Historias secretas del racismo en México. 1920-1950. México: Tusquets; 2007, y el análisis de la relación entre el discurso científico y la teoría social de Cházaro, Laura. Dos fuentes de la sociología mexicana: el caso de Porfirio 
Precisamente, ese es el marco en el cual se mueve este texto; su objetivo, mostrar que el lenguaje de la ciencia no constituye una plataforma neutra de observación sino que posee un lugar específico en el mapa y que éste corre en estrecha relación con la expansión europea por el mundo ${ }^{2}$. Y para mostrarlo parto de un estudio de caso. A diferencia de los estudios que desde una perspectiva más sociológica presentan el panorama general de la constitución de las ciencias en América Latina ${ }^{3}$, o de aquellos que siguiendo los lineamientos de la historia de las ideas analizan, por ejemplo, el pensamiento liberal y positivista en México ${ }^{4}$, aquí presento un estudio de caso ejemplar, diría, en tanto que su singularidad puede hacer inteligible cierto contexto histórico.

Concretamente, me interesa el discurso médico mexicano del último tercio del siglo XIX, la forma cómo éste delineó una idea de ciencia donde la nación y la historia resultaban actores insoslayables. Pero habría que senalar que más que del «discurso», así en abstracto, hablo de «los médicos», especialmente de cómo uno de ellos puso ese discurso en acción y tomó posesión de la lengua. En la obra de ese médico busco detectar algunas de las operaciones discursivas que fueron armando el lazo entre la ciencia, la historia y la nación, tres conceptos que en una trama difícil de desentrañar, han delineado, en buena medida, el vínculo que la modernidad construyó entre naturaleza, política e historia.

El caso es el de Porfirio Parra, un médico que nació en 1854, que vivió «el porfiriato», el largo régimen de Porfirio Díaz (1876-1910), y que murió en 1912, un año después de que Díaz, luego de más de treinta años en el poder, saliera exiliado a Francia ante el estallido de lo que se conoce como la Revolución Mexicana. El último tercio del siglo XIX fue pues la época de Parra, un momento de respiro, digamos, después de casi un siglo de guerras

Parra y Rafael de Zayas y Enríquez. In: Estudios de Teoría e Historia de la Sociología en México. México: UNAM y UAM/A; 1995, p. 3-28.

2. Castro-Gómez, Santiago. La hybris del punto cero. Ciencia, raza e ilustración en la Nueva Granada.1750-1816. Bogotá: Pontificia Universidad Javeriana; 2010.

3. Me refiero a los trabajos de Quijano, Aníbal. Colonialidad del poder, eurocentrismo y América Latina. In: Lander, Edgardo, comp. La colonialidad del saber. Dominicana: CLACSO; 2000; Mignolo, Walter D. Historias locales/diseños globales. Colonialidad, conocimientos subalternos y pensamiento fronterizo. Madrid: Akal; 2003 y De Sousa Santos, Boaventura. Una epistemología del Sur. Buenos Aires: Siglo XXI; 2009, entre otros.

4. Hale, Charles A. La transformación del liberalismo en México a finales del siglo XIX. México: Vuelta; 1991 y Zea, Leopoldo. El positivismo en México: nacimiento, apogeo y decadencia. México: FCE; 1988 [ed. original 1968]. 
civiles e intervenciones extranjeras, un periodo de estabilidad y progreso económico, posible luego de que el gobierno de Díaz puso freno al proceso de desintegración política del país que la guerra de Independencia había desatado $(1810)^{5}$.

Pero si hay que presentar a Parra, entonces habría que decir, antes que nada, que fue «el discípulo dilecto» de Gabino Barreda, conocido por todos, por sus colegas y por los historiadores actuales, como el introductor del positivismo en México y el fundador de la Escuela Nacional Preparatoria, la escuela en el que Parra cursó el bachillerato y la plataforma a partir de la cual la educación superior sería reorganizada de acuerdo con la doctrina positivista ${ }^{6}$. Todos aquellos que lo conocieron refieren a la fuerza de ese vínculo que lo unía a Barreda ${ }^{7}$. De hecho, eso es lo primero que sus colegas resaltan. Francisco A. Flores, por ejemplo, el médico que escribió la primera historia de la medicina mexicana, veía en Parra a un joven profesor de «una gran inteligencia, un profundo estudio y una vastísima instrucción», de «gran esperanza para la ciencia y para la patria», «uno de los mejores discípulos del Dr. Barreda», y uno de los «más esforzados adalides de la Filosofía científica o positiva» ${ }^{8}$. Samuel García, colega suyo también, recuerda, en una semblanza escrita el año de su muerte, cómo en la Escuela Nacional Preparatoria esos «dos cerebros privilegiados», el de Parra y el de Barreda, «hechos para comprenderse», «vibraron uniformemente estableciéndose

5. Sin posibilidades de contar aquí la historia del siglo XIX mexicano, la dibujo sólo con un fragmento tomado del excelente estudio de Palti: «Casi inmediatamente después de la Independencia, el sistema político mexicano entró en un proceso acelerado de descomposición que hacia mediados del siglo alcanzó casi el punto de su total desintegración (punto a partir del cual comenzaría su penosa reconstrucción)». Palti, Elías José. La invención de una legitimidad. Razón y retórica en el pensamiento mexicano del siglo XIX. (Un estudio sobre las formas del discurso político). Argentina: FCE; 2008, p. 43. Sobre la visión del siglo XIX por parte de la historiografía mexicana ver también Tenorio-Trillo, Mauricio. Argucias de la historia. Siglo XIX. México: Paidós; 1999; y González Navarro, Moisés. El Porfiriato. La vida social. In: Cosío Villegas, Daniel. Historia moderna de México, México: Hermes; 1957, vol. 4, 979 p.

6. Al respecto ver Hale, $n$. 4, especialmente el capítulo 2, «La estructura de la política científica», p. 51-111.

7. Un vínculo sellado pues según cuenta Parra en 1875 se contagió de tifo, y después de que tres importantes médicos declararon que no había nada que hacer, Barreda reconoció el caso, formuló una indicación y «desaparecieron como por encanto los síntomas graves». "Yo mismo soy un testimonio viviente de la pericia médica de mi maestro». Parra, Porfirio. El Sr. Barreda médico y profesor de la Escuela de Medicina. Boletín de la Escuela Nacional Preparatoria. 1909-1910; 2: 161-163 (163).

8. Flores, Francisco A. Historia de la medicina en México. México: Secretaría de Fomento; 1886, vol. 3, p. 524. 
una corriente de actividad» entre ellos $^{9}$. Eso es también lo primero que apuntan sus biógrafos actuales: Parra fue el "positivista más reconocido de su tiempo» ${ }^{10}$, el médico que sustituyó a Barreda en la cátedra de lógica de la Escuela Nacional Preparatoria ${ }^{11}$, el que junto a Barreda estableció los fundamentos del positivismo, una perspectiva que «continuará orientando el sentido filosófico de la ciencia mexicana» por mucho tiempo ${ }^{12}$.

Pero más allá de su condición de discípulo, Parra fue un gran profesor y sus clases, cuentan algunos, un «espectáculo inolvidable» ${ }^{13}$; además, escribió libros de texto, estudios filosóficos, históricos, médicos y psiquiátricos, prólogos, poemas, una Oda a las matemáticas y una novela; participó en cantidad de asociaciones científicas, artísticas y literarias; fue funcionario del gobierno de Díaz, viajó a París en múltiples ocasiones y una vez a Moscú; fue varias veces diputado y senador y sirvió a Díaz, sobre todo en sus últimos años, aunque algunos consideren que a pesar de colaborar con la dictadura conservó siempre cierto sentido crítico ${ }^{14}$.

Sin duda, Porfirio Parra fue un médico inquieto, activo y muy versátil; sin embargo, me interesa menos esa versatilidad que la parte de su vida que dedicó a la «filosofía médica», o como él mismo solía llamarla, a la "psicología del conocimiento». Creo que es eso lo que lo distinguió de los demás médicos de su generación, el hecho de haber sido el único que después

9. García, Samuel. El Dr. Porfirio Parra. Gaceta Médica de México; 1912; 7: 356.

10. Matute, Alvaro; Trejo, Evelia. La historia Antigua en México: su evolución social. Estudios de Historia Moderna Contemporánea de México [libro en internet]. S/f; 14: 182. Disponible en: http://www.historicas.unam.mx/moderna/ehmc/ehmc14/182.html [citado 6 Nov 2012].

11. Alvarado, Lourdes. Porfirio Parra y Gutiérrez. Semblanza biográfica. Estudios de Historia moderna y contemporánea de México [en línea].México: UNAM-Instituto de Investigaciones Históricas; 1988; 2: 183-199. Disponible en: http://www.iih.unam.mx/moderna/ehmc/ehmc11/141.html [citado 6 nov 2012].

12. Viesca, Carlos. Las ciencias médicas en el México Independiente. In: Aréchiga, Hugo; Somolinos, Juan, comps. Contribuciones mexicanas al conocimiento médico. México: FCE; 1993, p. 59-84 (73).

13. Antonio Ramos Pedrueza, citado por Alvarado, n. 11, p. 12.

14. Alvarado, n. 11. Además de este trabajo, éstos son algunos de los artículos que recogen la biografía de Porfirio Parra: Rodríguez de Romo, Ana Cecilia; Castañares, Gabriela; Robles, Rita. Protagonistas de la medicina científica mexicana. 1800-2006. México: Facultad de Medicina, UNAM/ Plaza y Valdés Editores; 2008, p. 354-355. Aragón, Agustín. Diez retratos literarios de médicos mexicanos eminentes. México: Imprenta del Departamento de Salubridad Pública; 1933, p. 25-27. Martínez, José Luis, ed. Semblanzas de Académicos. Antiguas, recientes y Nuevas. México: FCE; 2004. 
de Barreda acompañó su trabajo clínico con la reflexión alrededor de los métodos, los principios y las reglas del conocimiento médico y científico.

Pero tengo que especificar más: de la vasta obra de Parra tomo aquí sólo un ángulo, aquel que dedicó no a la ciencia sino a la historia de la ciencia en México, una rama que, en sus propias palabras, era estudiada en Europa pero que en México y América aún no había sido colocada la primera piedra. El eje del análisis lo constituyen sobre todo dos textos, uno, el «Prólogo» a La historia de la medicina en México de Francisco A. Flores (1886), la primera historia general de la medicina mexicana que abarca desde la época prehispánica hasta el presente ${ }^{15}$; y el otro, el artículo «La ciencia en México» publicado en México, su evolución social, obra dirigida por Justo Sierra ${ }^{16}$. El primero, el «Prólogo», forma parte de una obra que, según palabras de Parra, reúne en un conjunto «lo que el arte médico ha sido en diversas épocas entre nosotros», que presenta «como de bulto» el desarrollo de la medicina en México a lo largo de cuatro siglos, y que «hubiera cerrado dignamente la carrera gloriosa del más ilustre veterano de la ciencia» ${ }^{17}$. «La ciencia en México», en cambio, fue publicado veinte años después en México, su evolución social, una obra que se presenta a sí misma como un «inventario monumental que resume en trabajos magistrales los grandes progresos de la nación en el siglo XIX», y que los historiadores actuales consideran el «monumento más representativo del Porfiriato» ${ }^{18}$.

Para empezar, los dos textos de Parra tienen en común el hecho de formar parte de obras monumentales. Y digo «monumentales» no sólo porque así las calificaron sus propios autores, sino también porque ambas, tanto La historia de la medicina en México como México, su evolución social, pretendían ir más allá de los datos históricos para presentar una historia general organizada en función de una «una idea filosófica», es decir, de una generalización. Son monumentales porque ambas siguen un planteamiento teórico cuyo fundamento es positivista, y porque desde México apelan a la historia universal. Así, la primera de ellas organiza los datos históricos de

15. Parra, Porfirio. Prólogo. In: Flores, n. 8, p. 9-31.

16. Parra, Porfirio. La ciencia en México. In: Sierra, Justo, dir. México, su evolución social. Inventario monumental que resume en trabajos magistrales los grandes progresos de la nación en el siglo XIX. Tomo 1; México: Porrúa; 2005, p. 418-466 (ed. original 1902).

17. «¿Cómo no ha de tener atractivo un libro que nos presente como de bulto el importante desenvolvimiento de nuestras ciencias médicas al través de cuatro siglos?» Parra, n. 16, p. 18-20.

18. Matute; Trejo, n. 10, p. 1. 
acuerdo con la famosa generalización conocida con el nombre de «ley de los tres estados», por los cuales, según Auguste Comte, «uno de los filósofos más insignes del presente siglo», decía Parra, transita la humanidad (teológica, metafísica y científica) ${ }^{19}$, mientras que la segunda prefiere distanciarse de la organización cronológica que caracterizó a México a través de los siglos, la otra gran síntesis histórica del Porfiriato escrita once años atrás, para optar por la división temática ${ }^{20}$. De cualquier manera y pese a sus diferencias, esas dos obras monumentales se proponen ir más allá de la cronología de los acontecimientos a fin de presentar una visión general de la historia. Precisamente eso es lo que Parra admiraba del trabajo de Flores:

«Allí los hechos narrados no se presentan en confuso hacinamiento y unidos al acaso como en los pesados cronicones de la Edad Media, sino que una idea filosófica, cerniéndose sobre las páginas de este libro, coordina en un conjunto armonioso las muchas y diversas partes de que se compone tan vasto material» ${ }^{21}$.

Con esos dos textos como punto de partida intento establecer conexiones que me permitan entender cómo es que la ciencia, la historia y la nación se fueron fundiendo hasta volverse indistinguibles. En última instancia, me gustaría empezar a desbaratar la con-fusión entre esos tres conceptos, y me gustaría también, a través de esas conexiones, acercarme al modo cómo la ciencia europea se leyó en México, esto es, al tamiz ideológico a través del cual esas nuevas ideas adquirieron sentido en México $^{22}$. Y para ello el positivismo, esa doctrina de la que hoy las ciencias sociales y especialmente los estudios culturales quieren desprenderse, y a la que Parra se adhirió abiertamente, constituye el marco de referencia fundamental. Y es que en el último tercio del siglo XIX esa doctrina definió las ideas de realidad, objetividad y universalidad sobre las cuales un médico como Parra concibió los conceptos de historia, ciencia y nación. Pero esto no significa que haya optado por encerrar el caso en su particularidad, como si México fuese una entidad clausurada que sólo obedece a la determinación de su propio

\footnotetext{
19. Parra. n. 15, p. 29.

20. Riva Palacio, Vicente, dir. México a través de los siglos. Historia general y completa del desenvolvimiento social, político, religioso, militar, artístico, científico y literario de México desde la antigüedad más remota hasta la época actual. 5 vols. México: J. Ballescá y Compañía; 1884.

21. Parra, n. 15, p. 28

22. Castro-Gómez, n. 2.
} 
contexto. Más bien diría que buscó la manera de salir de esa clausura en la que, según Claudio Lomnitz, los científicos sociales mexicanos, sobre todo los historiadores, hemos estado atrapados sin conseguir traspasar las fronteras de lo que alguna vez Andrés Molina Enríquez llamó «los grandes problemas nacionales» (1908), mientras los norteamericanos o los europeos le dan forma a la racionalidad universal ${ }^{23}$. En ese sentido, desde un estudio de caso intento plantearle al conocimiento una pregunta general que tiene que ver con la relación entre lo particular y lo general, entre la ciencia y la historia, o para decirlo en términos de Parra, entre la fisiología y la biología.

Con ese propósito divido el trabajo en tres partes: primero la Ciencia, luego la Historia y por último la Nación.

\section{La Ciencia}

Parra consideraba que había llegado el momento de que la Ciencia sustituyera a la Historia, y que la Realidad ocupara el lugar de la Retórica ${ }^{24}$. Pues en el último tercio del siglo XIX la retórica, ese arte del discurso cívico, esa tradición más afín a los abogados pero para nada ajena a los médicos, terminaría siendo borrada por la ciencia, convertida ya entonces en el único modo aceptado de conocer el mundo ${ }^{25}$.

Sin duda, la concepción de la historia había cambiado. Y si se trata de poner una fecha, ese cambio, diría, tuvo lugar el 16 de septiembre de 1867, el día en que, en Guanajuato, cuna de la Independencia, Gabino Barreda pronunció su famosa Oración cívica, un discurso conmemorativo y, simultáneamente, un proyecto por venir:

«Conciudadanos: En presencia de la crisis revolucionaria que sacude al país entero desde la memorable proclamación del 16 de septiembre de 1810 [...] una necesidad se hace sentir por todas partes: la de librar a la historia de los caprichos providenciales y del azar para sujetarla a las leyes de la ciencia» ${ }^{26}$.

23. Lomnitz, Claudio. Deep Mexico, Silent Mexico. An anthropology of nationalism. Minneapolis; London: University of Minnesota Press; 2001, p. XI-XXII.

24. Parra, n. 16, p. 418.

25. Sobre la retórica: Palti, n. 5, p. 48.

26. Barreda, Gabino. La educación positivista en México. México: Porrúa; 1987, p. 17. 
Y esa era la consigna que Parra seguiría al pie de la letra: liberar la historia de la providencia, de la retórica y también del arte, porque el historiador no era más un escultor o un artista que modela la sociedad y la orienta moralmente, sino que aparecía ahora como un científico que acumula datos y además hace filosofía de la historia ${ }^{27}$. Más que la ordenación temática o cronológica de los hechos, Parra buscaba leyes, orden, una idea general, ya no retórica o metafísica sino positiva. De ahí que sobre la retórica colocara «la materia prima de la realidad», y sobre el azar y el «confuso hacinamiento» de datos, la generalización ${ }^{28}$.

Parra se veía a sí mismo como parte de una nueva generación que nacida en la segunda mitad del siglo XIX era el producto de una doble ruptura: primero con el pensamiento teológico y después con la metafísica, sobre todo con el vitalismo y la creencia de que existe «una fuerza vital superior a los órganos» ${ }^{29}$. Se sentía un hombre del XIX y le profesaba un amor excesivo a un siglo que había «creado las ciencias de la vida», que las había «fortificado y desenvuelto», dándoles «realidad y utilidad»; un siglo que estaba trazando «el plan de una nueva ciencia» fundada ahora en el principio de que «todos los fenómenos vitales, sean de la categoría y del orden que fueren, están subordinados a las condiciones orgánicas» ${ }^{30}$.

Claramente, Parra establecía la distancia con la generación que lo antecedía. La suya se distinguía por la aspiración de superar el empirismo y formular leyes generales. Pertenecía a una generación que había dejado atrás la rigidez de un pensamiento dominado por la anatomía y la historia natural, detenido en la descripción y clasificación de especies siempre estáticas, dispuesta a abrirse no sólo a la fisiología, la nueva ciencia de los procesos funcionales del organismo, sino sobre todo a la biología, la ciencia dedicada a explicar la vida en su totalidad. De ahí que criticara a sus colegas naturalistas, aferrados al mundo empírico, atrapados en lo fáctico, detenidos en el «rudo lenguaje de los hechos», sin posibilidades de acercarse a los lineamientos de la lógica y del método experimental e incapaces, por tanto, de elevarse, con «alas de cóndor», por encima del conocimiento de las cosas mismas y comprender las fuentes internas del entendimiento. Para él

27. Sobre las distintas concepciones de la historia: Koselleck, Reinhart. Futuro pasado. Para una semántica de los tiempos históricos. Buenos Aires: Paidós; 1993.

28. Parra, n. 15, p. 28

29. Parra, Porfirio. Fisiología y biología. Gaceta Médica de México. 1899; 36: $442-453$ (443).

30. Parra, n. 15, p. 444. 
la virtud de la ciencia positiva consistía precisamente en eso, en poseer un lenguaje universal que trasciende el lenguaje histórico, fuente de confusión y error, y capaz de reflexionar sobre su propia estructura.

De allí proviene seguramente su interés por «caracterizar y definir dos ciencias, la biología y la fisiología, capitales en el dominio de las ciencias médicas», y que para entonces el lenguaje científico confundía ${ }^{31}$. Parra creía que definiendo esos dos términos no sólo cesaría esa «lamentable confusión» sino que también quedaba asegurada la separación del lenguaje de la retórica y su conversión en un instrumento transparente capaz de determinar un significado fijo para cada cosa.

Con ese fin Parra escribió en 1899, en la Gaceta Médica de México, el artículo «Fisiología y Biología». Allí afirmaba que la confusión entre los dos términos provenía de haberle dado «a la voz fisiología una connotación general, que ella repugna», y al «concretar la significación eminentemente abstracta del vocablo biología», cuando en realidad la fisiología constituía la «ciencia concreta de la vida de una especie determinada», encargada de aplicar las leyes a la historia a los diferentes seres, mientras la biología, la «ciencia abstracta de la vida», "ciencia madre», tenía como finalidad formular las leyes generales que rigen las diversas clases de fenómenos ${ }^{32}$.

E inmediatamente después de su publicación, ese artículo desataría una pequeña controversia. Ese año Jesús Sánchez le respondió. Luego de que este médico naturalista y director por muchos años del Museo Nacional confesara que durante mucho tiempo no supo distinguir exactamente entre biología y fisiología ni «determinar la esfera de acción que a cada una correspondía», aceptaba que aunque la biología era «como una ciencia madre», en realidad formaba parte de la historia natural, la ciencia que «se ocupa de los animales y de las plantas o seres que tienen vida» ${ }^{33}$. Más tarde intervendría en la controversia Luis E. Ruiz, una suerte de árbitro que sin embargo inclinaría la balanza a favor de Parra. Le reclamaba a Sánchez el hecho de permanecer atrapado en el mundo de lo fáctico y aspirar sólo «al perfume de las rosas» sin recursos para ver «la totalidad del bosque». En cambio, veía en Parra al «sabio médico», al «genial filósofo», al «ilustre

31. Parra, n. 15, p. 445

32. Parra, n. 15, p. 446.

33. Sánchez, Jesús. Fisiología y Biología. Gaceta Médica de México, 1899; 36: 618-624 (620). 
obrero de la ciencia» que pudo «levantarse» por encima del conocimiento de las cosas mismas hasta alcanzar la dimensión de lo abstracto ${ }^{34}$.

Treinta años separaban a Parra de Sánchez, una generación completa, según los cálculos del primero, pues mientras Sánchez procedía como un naturalista y argumentaba mediante cuadros y clasificaciones, Parra decía seguir los lineamientos de la lógica y el método experimental. Si, como le criticaba Parra, a Sánchez le interesaba «la investigación de los hechos y (el) acopio del material científico, desdeñando, ciega a injustamente, la ideología que debe presidir a la coordinación de ese material», Parra se ocupaba de formular las bases filosóficas y científicas que sus colegas daban por sentado en su práctica clínica. Por eso, este médico conminaba a sus colegas a ir más allá del empirismo y tender «el vuelo hacia las zonas más altas de la investigación», tal como lo había hecho Claude Bernard, un hombre de laboratorio pero también un legislador y un filósofo de las ciencias médicas que no «acalla toda voz interior de su pensamiento para no escuchar otra cosa que el rudo lenguaje de los hechos» ${ }^{35}$.

Más allá de la taxonomía propia de la Historia Natural con sus cuadros de semejanzas y diferencias, la fisiología y la biología que Parra defendía debían reflexionar sobre la historia y el tiempo. Después de todo, era la época de la teoría celular, la embriología y la teoría de la evolución, doctrinas cuyo punto de referencia no eran ya las verdades intemporales de la creación sino el dinamismo de una naturaleza en permanente cambio ${ }^{36}$. Como ahora el énfasis estaba puesto en la perpetua modificación de las cosas, eran la fisiología y la biología, juntas, las que podían dar cuenta de la totalidad de la vida: mientras la primera era la encargada de estudiar el funcionamiento del organismo, la segunda respondía a la pregunta general por la unidad de la vida.

34. Ruiz, Luis E. Fisiología y biología. Gaceta Médica de México, 1900; 37: 467-472 (469).

35. Parra, n. 15, p. 445. En otro artículo decía: «A través de un trabajo de comparación entre todos los seres vivos, desde los más rudimentarios hasta los mejor organizados, deben las manifestaciones vitales compararse en todos los tejidos, en todos los órganos, en todos los elementos histológicos; y las condiciones, y los caracteres, que tal comparación demuestre ser constantes en todos los casos, expresados esos caracteres en un lenguaje claro, sencillo, preciso, constituirán una definición de vida (...) Como se ve, tal operación debe estar basada esencialmente en los hechos, debe ser un trabajo de comparación, de análisis, de generalización». Parra, Porfirio. Biología. Las definiciones de la vida. Gaceta Médica de México, 1892; 28: 226-235 (228-229).

36. Coleman, William. La biología en el siglo XIX. Problemas de forma, función y transformación. México: FCE; 2002. 
Entre la fisiología y la biología Parra había construido un vínculo causal. Mostraba cómo entre lo particular y lo general, entre el funcionamiento del organismo y la definición de la vida, existía una secuencia que encadenaba hechos particulares, empíricos, y de esa manera construía una línea continua e indeterminada que respondía a la pregunta general por la vida ya no desde el vitalismo sino a partir de las condiciones por las que se pueden producir o modificar fenómenos empíricos. De ahí que se pueda afirmar que Parra estaba aún lejos de Darwin cuya temporalidad era más abierta a vicisitudes y contingencias, pero cerca de Comte, para quien el tiempo era uniforme y absoluto, en tanto que el cambio se regía por un conjunto de leyes generales y objetivas susceptibles de ser descubiertas. Por eso, cuando Parra dice «elevarse», se está refiriendo a eso: a tomar el mundo fenomenal como punto de partida y, a través de sucesivas comparaciones y secuencias causales entre hechos, formular leyes universales.

De hecho, podría afirmar que toda la obra de Parra se encamina hacia ese fin, a demostrar que lo general y lo particular podían unificarse en una única operación metódica; o para decirlo con sus palabras, que la inducción y la deducción constituían una misma operación lógica. Y lo creía así porque, a diferencia de Bernard quien separaba estos dos procedimientos, consideraba que la ciencia positiva ofrecía al mismo tiempo «la materia prima de la realidad» y la ley general; esto es, que la realidad empírica y la idea sobre esa realidad eran la misma cosa. O de otro modo, que las leyes estaban ancladas en la naturaleza misma porque la realidad se manifestaba en leyes generales.

Y precisamente porque la Ciencia era espejo de la realidad y simultáneamente teoría del conocimiento, podía ocupar el lugar de la Historia y convertirse en el saber supremo, en el único cuyo lenguaje podía demostrar cómo la realidad empírica reflejaba la estructura universal. Y aquí, me parece, reside el núcleo del positivismo, en esa plataforma neutra de observación, punto cero a partir de la cual el mundo se vuelve empíricamente objetivo y puede al mismo tiempo ser nombrado en su esencialidad.

\section{La Historia}

De entrada, se podría decir que la historia que Parra cuenta, evoluciona, apunta hacia adelante y anuncia un futuro prometedor. Esa es su estructura temporal; de ahí que su historia dibuje un proceso paulatino de elevación, el 
mismo del «gran Newton, elevándose a la vertiginosa altura de lo sublime», similar al trayecto de un barco que «tras surcar revueltos mares llega al puerto», el mismo trayecto de la medicina mexicana, «nave atrevida» que prosigue «su serena marcha hacia el progreso» ${ }^{37}$. Como sea, el caso es que la promesa está puesta en el cielo o en el puerto y que lo demás, es decir, los episodios o los acontecimientos mismos, sólo configuran la secuencia que hay que seguir para cumplirla.

De esta manera, en su concepción de la historia, el progreso es la única temporalidad posible y esa temporalidad conjuga, al igual que la ciencia positiva, dos ámbitos: por un lado, lo particular, en tanto que el progreso acumula y encadena en una línea causal fenómenos empíricos, y por otro lado, lo general, en tanto que garantiza desde fuera la finalidad hacia la cual esa línea continua se dirige. Así, el progreso está al mismo tiempo afuera y adentro de la historia, de ahí que pueda unificar los hechos empíricos con la teoría general, la fisiología con la biología. Y el motor que mueve esa historia es la oposición que enfrenta lo abstracto y lo concreto, dos mundos, dos maneras distintas de concebir el saber y la cultura.

Por eso, cuando Parra escribe historia de la ciencia está contando la historia de México, ahora dividida en dos, partida entre el mundo prehispánico, concreto, pre-científico, sin escritura, de conocimientos empíricos surgidos de la necesidad y reducidos a lo que los sentidos pueden mostrar, y Occidente, un mundo abstracto, poseedor de «la sabia lengua española» y de la ciencia. Y el momento que separa ambos mundos es el siglo XVI, momento en que los españoles traen al Nuevo Mundo su lenguaje y su religión y cuando la «ciencia propiamente dicha, formada por un conjunto de doctrinas comprobadas y expuestas con claridad y precisión, y por un método adecuado a cada categoría de fenómenos» y que los aztecas jamás conocieron, se hace presente en México ${ }^{38}$. Allí comienza la historia verdadera, una cuya finalidad no es otra que conseguir que lo abstracto se imponga sobre lo concreto, de la misma forma como la cultura española se impuso sobre la nativa.

Por eso, en la oposición entre lo abstracto y lo concreto, Parra desplaza hacia el ámbito del saber otra oposición que divide la historia universal entre lo civilizado y lo bárbaro, lo tradicional y lo moderno, términos cuya

37. Parra, n. 15, p. 21.

38. Parra, n. 16, p. 424. 
relación está dada en función de una jerarquía: arriba, en la parte superior, queda la civilización occidental, y abajo, en la escala más baja de la historia, en la prehistoria, los «salvajes de América», carentes de pensamiento filosófico, «rara amalgama de cultura y de barbarie» que le hace pensar «en los salvajes más ínfimos» ${ }^{39}$. Aunque en la civilización azteca reconoce «evidentes destellos de adelanto», no le satisfacen muchas de las conclusiones a las que por ejemplo llega Flores en La historia de la medicina en México: ni aprueba ciertas ideas ni siente entusiasmo «por el grado de cultura que alcanzó la civilización azteca» ${ }^{40}$. De ahí que en el «Prólogo» se distancie de esa "civilización tan rara» mientras que en «La ciencia en México» borre directamente un mundo que ya en el anterior consideraba «apenas un islote miserable que asoma tímidamente en el océano sin playas de lo desconocido y de lo ignorado» ${ }^{41}$. Y eso es lo que precisamente algunos historiadores actuales le han criticado, el hecho de haberle negado al mundo prehispánico su «contribución al legado nacional» ${ }^{42}$.

Pero más allá de esa oposición, lo que resalta en esa versión de la historia es la manera de concebir el cambio histórico. Pues en este caso, los episodios no aparecen unidos por una continuidad sino que están separados por una ruptura abrupta, tajante, tan radical que, de acuerdo con Parra, pocos «cambios habrá en la historia que hayan transformado más completamente una sociedad» como aquel en el que «las riendas del gobierno pasaron de las manos débiles del supersticioso Moctezuma II a las viriles de D. Antonio de Mendoza» ${ }^{43}$.

En realidad, en esa historia el origen no está en el siglo XVI y el comienzo de la colonización sino en una fractura profunda, contundente, que hace que el mundo indígena, débil, femenino, bárbaro, desaparezca ante la fuerza del mundo occidental, viril y masculino. Y lo que sucede después es que ese origen se repetirá a manera de réplica en la guerra de Independencia, cuando Europa se impone sobre el régimen colonial, y se repetirá nuevamente a mediados del siglo XIX cuando, sobre una ciencia detenida en la descripción del fenómeno mismo, incapaz de ver más allá de los pro-

\footnotetext{
39. Parra, n. 15, p. 20.

40. Parra, n. 15, p. 27.

41. Parra, n. 15, p. 13

42. Moya López, Laura Angélica. La nación como organismo. México. su evolución social. 19001902. México: UAM-A/Porrúa; 2003.

43. Parra, n. 15, p. 22.
} 
blemas relativos a la experiencia de la vida humana, se impone la ciencia «positiva y experimental», es decir, filosófica y empírica al mismo tiempo.

Por eso, pareciera que más que seguir los eslabones de una línea evolutiva, la historia de Parra se mueve entre fracturas. De ese modo pueden leerse sus textos, no desde la continuidad que une los distintos episodios, sino desde el vacío que queda entre ellos; y en esa lectura lo que resalta no es tanto la gradualidad de un proceso sino la sucesión de fracturas, réplicas de una ruptura primera, fundacional:

«Los audaces conquistadores derrumban esa civilización al filo de sus aceros, al recio acometer de sus caballos y entre el ensordecedor estrépito de sus armas de fuego; y sobre sus ruinas fundan la nueva sociedad cristiana; y en pos de los feroces sacerdotes de Huitzilopochtli vienen los mansos y caritativos sacerdotes de Cristo; y en pos de las pinturas y jeroglíficos aztecas viene la escritura, cuya invención atribuye la fábula a Cadmo, y en pos de la melodiosa lengua azteca, el español sonoro y las lenguas sabias, vehículos del saber de Europa» ${ }^{44}$.

Podría decirse entonces que en eso consiste la particularidad de la historia de México que Parra cuenta, en lo profundo, lo radical de cada una de esas rupturas:

«Y en el particular caso a que nos estamos refiriendo, las dificultades crecen, no tanto por el número de cambios, cuanto por lo profundo, por lo radical, por lo completo que cada uno de ellos fue: primero la civilización hispana derrocando la azteca y erigiéndose sobre sus ruinas; después el torrente de ideas que agitan a la Europa contemporánea, precipitándose desbordado y ensordecedor por el estrecho cauce en que antes corría mansamente el régimen colonial» 45 .

La particularidad de la historia de México depende así de la profundidad de la fractura, es decir, del tamaño de la destrucción. Pues a diferencia del Imperio Romano donde se conservaron monumentos y saberes, en México, asegura Parra, la cultura indígena fue arrasada, devastada, «desaparecieron mil testimonios y mil testigos enmudecieron", y "no le sobrevivió ningún influjo duradero»: 
«Es verdad que estas tierras no eran baldías cuando los españoles llegaron a sus playas. Razas vigorosas, venidas no se sabe de dónde, se habían establecido en ellas, fundando un imperio poderoso; más ese imperio fue arrasado por los conquistadores, y no le sobrevivió ningún influjo duradero. Nada de lo que culmina en la actual nación mexicana se debe a la civilización aborigen» ${ }^{46}$.

Por eso, en lugar de una secuencia progresiva que se eleva por encima de las rupturas, esa historia de México, podría decirse, se mueve a través de mutaciones radicales, de catástrofes, por lo que resulta difícil aceptar la idea sostenida por algunos historiadores actuales en el sentido de que Parra compartió «la aspiración sobre la búsqueda de un pasado común, lineal e integrado por un vínculo cultural y racial que recorría las etapas más significativas de la historia mexicana, desde la época prehispánica hasta aquel presente porfirista» ${ }^{47}$. Y es que, me parece, más que la figura de un barco que marcha serenamente entre mares agitados, su historia está hecha de ruinas: la Colonia que se levanta sobre los restos de la cultura prehispánica, y la Independencia que necesita de la destrucción de la Colonia. Cada episodio parece constituirse a partir de la negación del anterior, como si el acto de borrar fuera la condición indispensable para que el barco llegue a puerto, la Ciencia se fusione con la Historia y el lenguaje científico nombre por primera vez el mundo. Lo propio de la historia nacional estaría así en ese acto simultáneo de destrucción, negación y abolición: la historia científica que expulsa primero al mundo prehispánico del tiempo histórico, y que expulsa después al régimen colonial ya no del tiempo sino de la historia nacional. Para Parra estas serían las «condiciones especiales [en que] se ha desarrollado nuestra nacionalidad ${ }^{48}$.

\section{La Nación}

El acto de borrar el pasado se convertía así en la condición necesaria para insertar a México dentro de los cauces de la historia universal: hay que encapsular el pasado para que en el futuro la civilización se imponga sobre la barbarie. Así lo diría Parra: hay que desalojar la historia de «un pasado

\footnotetext{
46. Parra, n. 16, p. 422.

47. Moya, n. 42, p. 107

48. Parra, n. 15, p. 20
} 
que se aborrece» y enturbia el porvenir ${ }^{49}$; hay que olvidar si lo que se busca es insertar al país en la línea del progreso; no queda más alternativa que aplicar el método científico a «toda clase de fenómenos» si lo que se quiere es salir de la anarquía y levantar «el gran edificio de la reconstrucción». Con respecto a la ciencia sí tenía claridad:

«hemos creído que sólo el método científico, franca y explícitamente aplicado a los fenómenos sociales, sería la segura panacea de los presentes males, sería el iris de la serena paz, que marca el fin de la tormenta $»^{50}$.

Sin embargo, por paradójico que parezca, eso que es necesario borrar para que la civilización llegue, define justamente la particularidad nacional, esto es, aquello que nos pertenece exclusivamente y nos hace diferentes a los demás. Parra tenía que admitirlo, algo de la prehistoria perduraba en el presente:

«la cultura indígena aunque proscrita y lanzada de todos los terrenos de la manifestación externa, ha de haber subsistido como modificación interna en el ánimo de la raza vencida contemporánea de la conquista y transmitiéndose más o menos modificada de generación en generación, por medio de las íntimas confidencias del hogar y de las fáciles, estrechas y gratas vías de comunicación en que es tan pródiga la familia» ${ }^{51}$.

Reconocía que «muchas opiniones, que muchas supersticiones, que muchas costumbres de los indígenas hoy, provienen por filiación directa de ciertas opiniones, supersticiones y costumbres de la época de su soberanía ${ }^{52}$, y que ese pasado remoto, prehistórico, ajeno a la historia, afectaba no sólo a los grupos indígenas sobrevivientes sino que perduraba «como modificación interna» agitando a la totalidad del presente.

Borrando el pasado el positivismo se convertía en programa político, tal como Comte lo había prescrito en 1848: «El positivismo consiste esencialmente en una filosofía y una forma de gobierno, las cuales son inseparables por necesidad ${ }^{53}$. El problema es que al borrar ese pasado

49. Parra, Porfirio. Prólogo. Anales de Asociacion Metodófila. México: Imprenta del Comercio de Dublán y Chávez; 1877, p. 7, citado por Zea, n. 4, p. 54.

50. Parra, n. 15.

51. Parra, n. 15, p. 23

52. Parra, n. 15, p. 23

53. Hale, n. 4, p. 242. 
se borraba también la esencia del ser nacional, una esencia definida en función de una marca cuya procedencia era un tiempo «obscuro y difícil», la época anterior a la conquista, necesaria cuna y forzosa raíz de innumerables factores de nuestra actual constitución social». De hecho, en eso consistía la diferencia que separaba a México de los Estados Unidos, esa «gran República» que fue «implantada sobre un terreno cuya superficie se limpió. ¡Cuán distinto es lo que sucede entre nosotros! La sangre indígena circula por nuestras venas mezclada en proporción mayor o menos con la sangre europea; la raza indígena pura constituye un elemento considerable en nuestra población» 54 .

Siguiendo a Parra se podría decir entonces que un «resto» prehistórico se agita en aguas profundas; una suerte de capa de suciedad no removida a tiempo delinea eso que de «especial» tiene la historia nacional. Y la naturaleza de ese resto es muy peculiar ya que es invisible y natural al mismo tiempo, en la medida en que se transmite a través de las generaciones; es inmodificable en tanto que no es resultado de un proceso de adaptación o de una modificación proveniente de la vida social, sino que constituye un sustrato intacto en el tiempo. De ahí que me atreva a decir que el marco a partir del cual Parra concibe la historia de México está más lejos de la biología que de una fisiología aplicada a la historia de las comunidades humanas. En este sentido, la nación es concebida como un organismo vivo que nace, crece, decae y muere, al igual que un individuo:

«una agrupación humana, constituida en nación, está sometida a leyes análogas a las que rigen la vida de un individuo. A la una y al otro se pueden señalar un origen, un periodo de crecimiento y medro; luego uno de decadencia, que termina a la postre en la muerte y la disolución, así del individuo como de la agrupación de individuos» ${ }^{55}$.

Al final, su idea de nación se desprende de la fisiología, la ciencia encargada del estudio de las funciones y la estructura del organismo; o quizás de más atrás, de un vitalismo que cree en una sustancia teleológicamente orientada, o, más atrás aún, de la teoría de la preformación que supone que todos los estados posteriores del organismo están contenidos en su germen, esto es, que el proceso de gestación no es más que un mero crecimiento de

54. Parra, n. 15, p. 24.

55. Parra, n. 16, p. 418. 
rasgos depositados en el embrión ${ }^{56}$. De cualquier manera, sea entendida como organismo, como fuerza vital o como germen, la nación de Parra aparece como una «forma viviente» que siente y piensa, provista de instintos, pulsiones y estados de ánimo singulares pero naturales en tanto que funcionan independientemente de cualquier variable cultural o subjetiva:

«Ante hecho tan elocuente, ¿qué observador bien dotado no advierte, qué vigoroso pensador no concluye: que estos agregados humanos llamados pueblos y naciones, a semejanza de las agrupaciones celulares llamadas organismos, nacen, crecen y se desarrollan, gozan por cierto tiempo de la plenitud orgánica, y luego decaen, se marchitan y envejecen, y acaban por morir, devolviendo al Cosmos los elementos que los compusieron, para que sean más tarde incorporados a organismos nuevos?» 57 .

El problema es que una nación así, determinada fisiológicamente, requiere de un Estado que aparece no ya como el producto artificial de la libre elección de los individuos que le dieron origen, sino como un conjunto integrado de hombres que se comportan como un único individuo, espiritual y corpóreo a la vez ${ }^{58}$. La historia de una nación así no requiere de explicaciones complejas ya que éstas responden ahora a dinámicas ligadas a las necesidades de la especie. Por eso, para definir su particularidad, esa nación necesita no tanto de la antigua metáfora del estado-cuerpo de inspiración romántica, como de una fisiología patológica dirigida precisamente a determinar las «modificaciones primitivas de la propiedad fisiológica». Pues más que fundarse en un pasado común, lineal e integrado por un vínculo cultural y racial que recorre las etapas de la historia mexicana, como sostienen los historiadores actuales, la nación de Parra se funda en la persistencia de un núcleo sustancial, innato cuya naturaleza es patológica.

En sus términos, los restos de esa «civilización singularísima» que sobrevivieron a la destrucción no sólo son de naturaleza patológica sino que además tienen el poder de revertir la línea de la evolución, obligándola a caminar hacia atrás hasta ponerla nuevamente en contacto con la animalidad. Porque sin dudarlo mucho Parra se adscribió a las teorías degeneracionistas y creyó en "precondiciones fisiológicas», en «organizaciones defectuosas»,

56. Sobre las teorías preformacionistas: Palti, José Elías. La nación como problema. Los historiadores y la «cuestión nacional». Buenos Aires: FCE; 2002, p. 32.

57. Parra, n. 16, p. 419.

58. Esposito, Roberto. Bios. Biopolítica y filosofía. Buenos Aires: Amorrortu; 2006, p. 28. 
en «sellos morbosos» que ciertos individuos portan desde su nacimiento y transmiten a sus descendientes; creyó también que esa patología innata se extendía mediante la herencia hasta definir la naturaleza de poblaciones enteras ${ }^{59}$.

Eso es lo paradójico, que la historia de Parra mira hacia el futuro mientras palpa casi la degeneración progresiva de la raza, que recorre los episodios de una secuencia gradual de progreso, cuando de pronto, en un giro, voltea hacia atrás entregada a un trayecto regresivo e imposible. Una regresión que hay que decir podía suceder a través de dos vías: o la herencia morbosa se acumula a través de las generaciones en un proceso degenerativo, o esa misma herencia brinca atavísticamente entre generaciones. De otro modo: o la historia camina lentamente en un proceso de degeneración o se mueve a saltos, de fractura en fractura, de catástrofe en catástrofe.

De cualquier manera, ya sea que persista como el fondo de la historia o que irrumpa en ella intempestivamente, la «herencia morbosa»se reproduce a través de las generaciones y no cesa de afectar a los cimientos del presente. Porque para Parra la particularidad nacional remite a esa fuerza original que, más allá de razones de índole cultural o subjetiva, jala la historia no hacia fuera, hacia las metrópolis, sino hacia un pasado abismal que boicotea desde el interior cualquier posibilidad de progreso. De ahí que ante la pregunta de Justo Sierra, «¿dónde se localiza la causa de nuestra situación actual?» ${ }^{60}$, Parra pudiera responder: «no en lo adquirido

59. Sobre Parra y la teoría de la degeneración ver principalmente sus estudios sobre locura; uno de ellos el Ensayo sobre la patogenia de la locura. Tesis doctoral, México; 1878, p. 7-46. Sobre este tema ver mi trabajo de próxima aparición: Locura moral y degeneración: los caminos de la biopolítica. México en los finales del siglo XIX. In: Perspectivas en historia de las ciencias, los saberes y el cuerpo. Colombia: Universidad de Medellín-Universidad Eafit-Universidad de los Andes; en prensa. Sobre la teoría de la degeneración ver Chamberlin, Edward; Sander L. Gilman, eds. Degeneration. The dark side of pprogress, New York: Columbia University Press; 1985; Harris, Ruth. Murders and madness. Medicine, law, and society in the Fin de Siécle. Oxford: Clarendon Press; 1991; Huertas García Alejo, Rafael. Del «Ángel caído» al enfermo mental. In: Locura y degeneración. Psiquiatría y sociedad en el positivismo francés. Madrid: CSIC; 1987; Plumed Domingo, José Javier; Rey González, Antonio. La introducción de las ideas degeneracionistas en la España del siglo XIX. Aspectos conceptuales. Frenia. 2002; 2: 31-48; Urías, Beatriz. Locura y criminalidad: degeneracionismo e higiene mental en México posrevolucionario, 1920-1940. In: Agostoni, Claudia; Speckman, Elisa. De normas y transgresiones. Enfermedad y crimen en América latina (1850-1950). México: UNAM; 2005, p. 347-375.

60. Sierra, Justo. Evolución política del pueblo mexicano. México: Porrúa; 2009 (ed. original 1869), p. 281-311. 
sino en lo innato, en aquel elemento extra-histórico que permanece y se transmite por herencia».

Así, la historia de Parra se mueve entre dos registros, partida entre un pensamiento liberal ilustrado que tiene la mirada puesta en las metrópolis y el progreso y cuyo fundamento es un vínculo contractual entre individuos, y otro étnico-cultural, más cercano al romanticismo, que busca en el pasado el «espíritu del pueblo» ${ }^{61}$, pero que en este caso su fundamento es la idea de raza degenerada. Y, cabe decirlo, el hecho de moverse entre dos registros no convierte a Parra, como sostienen algunos, en un hombre de transición en cuyo pensamiento estén contenidas dos vertientes, dos estrategias teóricas y metodológicas ${ }^{62}$, más bien parecería que la historia que cuenta está sumida en la ambigüedad propia a todo nacionalismo, o mejor, en la ambigüedad del nacionalismo latinoamericano que dicho en una frase de Bikuh Parekh es políticamente anticolonial y culturalmente colonial $^{63}$. Pues aunque no lo diga abiertamente, Parra encuentra que la particularidad de la nación reside en un fondo histórico que subordina a su fuerza leyes, costumbres e instituciones; lo que significa que en este caso la ambigüedad liberalismo/romanticismo contiene debajo un sustrato orgánico, natural y patológico que aflora inevitable y sistemáticamente transmitiéndose a través de las generaciones. La nación de Parra, un rostro de dos caras en cuyo fondo subyace un determinismo racial. Su postura política, la misma que la de muchos de sus contemporáneos, la dictadura, la única forma de gobierno que en ese momento podía poner un freno a la anarquía del pasado y, simultáneamente, a la degeneración progresiva de la raza ${ }^{64}$.

\footnotetext{
61. Palti, n. 56, p. 29.

62. Cházaro, n. 1.

63. Fernández Bravo, Fernando, Introducción. In: La invención de la nación. Lecturas de la identidad de Herder a Homi Bhabha. Buenos Aires: Manantial; 2000, p. 11-23 (20).

64. Acerca de la raza ver especialmente Blanckaert, Claude. On the origins of French ethnology. In: Stocking, George W., ed. Bones, bodies, behavior. Essays on Biological Anthropology, Wisconsin: The University of Wisconsin Press; 1988, p. 18-55.
} 


\section{ARTICLES}

History, Science and Nation. A case study in 19th century Mexico

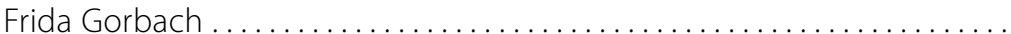

1.-Porfirio Parra, the case. 2.-Science. 3.- History. 4.-The Nation.

ABSTRACT: In an attempt to reflect on the political dimension of knowledge, I approach the Mexican medical discourse of the late 19th century and raise questions about the relationship that was built between the latter and history, science and nation. These three intricately woven concepts outline, in many ways, the relationship formed by modernity between nature, politics and history. For this purpose, I take the case of Porfirio Parra, one of the few Mexican physicians who reflected on the methods, principles and rules of scientific knowledge, and I attempt to show, based on his vast work, the way in which his understanding of science conceives of nation and history as inevitable actors. 